\title{
RESPONSABILIDADE POLÍTICA E A VISÃO DO OUTRO EM „ANDERSWO UNTERWEGS“, UM CONTO DE AYSEL ÖZAKIN
}

\section{Dionei Mathias $^{1}$}

Resumo: Este artigo pretende analisar o conto "Anderswo unterwegs" que integra a coletânea Das Lächeln des Bewußtseins, publicada em 1985 pela escritora Aysel Özakin. O interesse central deste artigo recai sobre o exame do papel da responsabilidade política e da visão do outro na concepção das personagens e sua apropriação da realidade intradiegética. Para isso, serão diferenciados três espaços nos quais a interação das personagens têm lugar: a pátria e os problemas da ditadura, o exílio e o novo contexto social, por fim, a intimidade e as dificuldades de diálogo. Esses espaços são concebidos como círculos que se estendem, aumentando o grau de responsabilidade e a necessidade de atentar ao outro.

Palavras-chave: Aysel Özakin; Das Lächeln des Bewußtseins; „Anderswo unterwegs“.

\begin{abstract}
This article aims to analyse the short story "Anderswo unterwegs", part of the collection Das Lächeln des Bewußtseins, published in 1985 by Aysel Özakin. It is interested in examining the role of political responsibility and the vision of others in the conception of its characters and their appropriation of intradiegetic reality. It identifies three spaces in which the interaction of characters takes place: the homeland and its dictatorship, exile and its new social context, finally, intimacy and its difficulties to dialogue. These spaces are understood as circles in which the degree of responsibility and the necessity of paying attention to others increase more and more.
\end{abstract}

Keywords: Aysel Özakin; Das Lächeln des Bewußtseins; „Anderswo unterwegs“.

\footnotetext{
1 Professor do Departamento de Letras Estrangeiras Modernas da Universidade Federal de Santa Maria - UFSM. E-mail: dioneimathias@gmail.com
} 


\section{INTRODUÇÃO}

Aysel Özakin certamente não é uma das autoras mais conhecidas da assim chamada "literatura de migração" ou "literatura intercultural" na Alemanha. Isso talvez resulte de suas opções linguísticas. Ao contrário de outros autores como Emine Sevgi Özdamar, Feridun Zaimoglu ou mesmo Herta Müller que se utilizam da língua alemã em seus escritos, para citar somente alguns dos mais célebres escritores desse campo literário, Özakin escreve seus textos em turco, alemão e inglês. De certa maneira, essa opção por uma determinada língua já encerra uma asserção política, pois indiretamente questiona a hegemonia dos discursos culturais com os quais dialoga. Ao optar pela língua materna num espaço em que esta tem de causar estranhamento, ela ignora a política de inclusão/exclusão tão importante para escritores pertencentes a grupo minoritários e afirma que a voz do outro é legítima em toda sua alteridade.

Özakin chega a Alemanha em 1981, três meses depois do golpe militar na Turquia. Antes de ir para Inglaterra, onde vive hoje, a autora publica alguns livros na Alemanha, dentre os quais as coletâneas de contos Soll ich hier alt werden? ('Envelhecer aqui?') em 1982 e Das Lächeln des Bewußtseins ('O sorriso da consciência') em 1985. Ambas escritas em turco e traduzidas posteriormente para o alemão. Em 1992, as duas coletâneas são publicadas num único livro, com um título que parece caracterizar uma das principais preocupações da autora: Deine Stimme gehört dir ('Tua voz te pertence'). Ou seja, como garantir a audibilidade da própria voz e respeitar a voz daquele que não se articula nos padrões dos discursos dominantes?

O conto "Anderswo unterwegs" ('Em outro lugar, a caminho') faz parte da coletânea Das Lächeln des Bewußtseins e aborda o reencontro de um jovem casal no exílio alemão. Narrado predominantemente a partir da perspectiva da jovem turca Diyana, o conto está estruturado em torno de três espaços nos quais os protagonistas assumem responsabilidade política e vislumbram o outro, num exercício de compreensão do lugar de ação: a terra natal, o exílio e o espaço da intimidade. Os diferentes espaços estão concatenados de forma associativa, isto é, com base nas experiências que a protagonista faz no presente diegético e a partir das reflexões sobre o outro e a própria voz.

\section{POSICIONAMENTO POLÍTICO NA TERRA NATAL}

A primeira sequencia narrativa expõe o reencontro do casal no exílio, concretizando para eles a vingança contra a ditadura que forçara sua separação (p. 139) ${ }^{2}$. Essa primeira informação sobre a vida pessoal revela sua visão de mundo e suas convicções políticas. No lugar de concentrar seu empenho na realização de uma existência comum na terra natal, construindo portanto um projeto de identidade que atenta, em primeiro lugar, às necessidades pessoais, os protagonistas se propõem estender seu escopo de visão e renunciar à

\footnotetext{
2 Todas as referências seguem o texto alemão: ÖZAKIN, Aysel. Deine Stimme gehört dir. Tradução do turco para o alemão de Hanne Egghardt e H. A. Schmiede. Hamburg: Luchterhand, 1992. As traduções para o português são do autor deste artigo.
} 
concretização imediata desse plano de vida. O olhar se distancia das coordenadas limitadas do projeto identitário particular para dirigir sua atenção a uma narração maior, centrada no espaço político e do bem comum.

Essa preocupação política não fecha os olhos diante da violência empregada pelos detentores de poder nem ignora a arbitrariedade inerente aos discursos que protegem a interpretação de realidade instaurada por eles. Sem ingenuidade, seu comportamento diante da realidade política do país encerra a consciência dos perigos atrelados à insubordinação, mas nem por isso os protagonistas procuram permanecer no lugar confortável da conivência passiva. Ao invés disso, antecipam a violência que o regime militar utiliza para silenciar aqueles que tentam subverter a ordem e cogitam a possibilidade de perseguição em suas projeções de futuro:

Ambos sabiam desde o momento em que se encontraram pela primeira vez, em que se tocaram pela primeira vez: José ou Diyana poderiam desaparecer repentinamente. José por causa de seu antigo trabalho no sindicato e por causa das falas que proferia em reuniões de trabalhadores; Diyana, como professora, por causa dos livros que dava a seus alunos e por causa dos encontros secretos com eles. Suficiente para a ditadura não mais largá-los (1992, p. 139).

Bem longes de uma narração de identidade arraigada na certeza ou na visão de um futuro com coordenadas pré-estabelecidas, os protagonistas suportam o desconforto de um projeto comum no marco da insegurança. A prioridade da concretização existencial, por conseguinte, não reside na obtenção célere de recursos (econômicos, sociais, anímicos) para a obliteração de receios indesejados na narração pessoal, mas dá preferência a uma reflexão que transcende os interesses que dizem respeito somente ao casal, optando por um caminho disposto a assumir a responsabilidade. Como professora e sindicalista, ambos exercitam um olhar solidário, com o fito de identificar a necessidade do outro e pensar o futuro do espaço social em que residem. Nisso, a imaginação de dois futuros (o particular e o público) se confrontam, sem medo de seguir o caminho mais árduo, a fim de garantir a liberdade de expressão identitária também a seus compatriotas.

A preocupação política com o espaço público se reflete também no comportamento exposto no espaço privado. Boa parte das memórias que a protagonista atualiza no exílio remonta ao envolvimento com a amiga, Perli. Esta se apaixonara por José, o atual companheiro da protagonista. O fato de Diyana rememorar os acontecimentos em torno desse episódio indica sua necessidade de esclarecer o passado, para integrá-lo de modo sustentável em sua narração de identidade. Essa tarefa se revela um tanto complicada, pois a amiga Perli lhe confidenciara o interesse que alimentava por José, antes que Diyana também se apaixonasse por ele. Desse conjunto de informações surge um conflito ético que a protagonista tem de resolver.

Livre do perigo de perseguição no exílio, ela encontra o ócio para analisar esse complexo narrativo com mais atenção. Característico para sua aproximação a esse passado perturbador é seu empenho em assumir a perspectiva da amiga, sem optar, de imediato, pelo caminho mais fácil do esquecimento ou da deturpação em prol de uma autoimagem positi- 
va. Em seu horizonte pessoal, desponta a possibilidade de culpa perante a amiga, porquanto houve um conflito de lealdade que se interpôs no processo de tomada de decisão. Sabendo do interesse da amiga, ela poderia ter se distanciado da pessoa em questão, a fim de não interferir na possibilidade de um relacionamento entre os dois. $\mathrm{O}$ acaso, a sequência de acontecimentos e a inegável atração que surge entre José e Diyana acabam unindo o casal. $\mathrm{Na}$ felicidade do reencontro e na segurança do exílio, contudo, Diyana não idealiza o passado nem diminui as consequências dessas ações para a vida da amiga (p. 166). Ela suporta o desconforto da incerteza acerca da culpa e assume sua responsabilidade diante dos acontecimentos, sem produzir memórias de tal forma concatenadas que o desconforto pudesse ser amenizado e posteriormente arquivado. Nisso, ela revela a mesma maturidade ética que já mostrara em seu engajamento político.

\section{IMAGENS DO EXÍLIO}

A fuga do regime militar e o recomeço de uma nova vida no exílio se revelam como grande chance para o casal, contudo, também trazem conflitos que dificultam a inserção no novo meio social. Ao contrário de José que já se encontra integrado na sociedade alemã, trabalhando como engenheiro e reunindo-se regularmente com seu círculo político de amigos, Diyana acaba de chegar ao país e precisa reorganizar sua existência. Ao abandonar o "país de sua infância e juventude" (p. 141) e encontrar-se repentinamente "numa espécie de vácuo" (p. 145), a protagonista se vê forçada a repensar sua narração identitária e idear novas sequências narrativas, a fim de calar a sensação de vazio. Com a exceção de José como elemento de ligação, ela não divisa possibilidades de imaginar o futuro, cercada de pessoas conhecidas e a partir do espaço de seu passado.

Esse momento de conflito pessoal se torna ainda mais tenso com as diferenças culturais e os problemas no país do exílio. Assim, o porteiro que não cumprimenta (p. 156), a impossibilidade de deparar-se com conhecidos nas ruas (p. 156) e a xenofobia acirrada com a crise no mercado de trabalho (p.162) representam elementos que questionam, de forma latente ou escancaradamente, sua presença naquele país e, com isso, também a legitimidade de seus ideais políticos. O tema da construção de identidade cultural e do domínio de verdades certamente representa um aspecto central da obra de Özakin, sendo examinado com profundidade pela crítica. Wagenbaur (1995) analisa a hibridismo cultural, Reeg (1997) se dedica à situação da escrita no novo contexto, Wierschke (1996a) caracteriza a escrita da autora como forma de autoasserção no processo conflituoso do diálogo entre culturas, Gökberk (1997) se detém sobre a alteridade e, por fim, Henderson (1997) estuda o conceito de pátria ('Heimat'). No conto aqui analisado, esses conflitos são somente indicados, uma vez que os protagonistas se encontram no processo inicial de assentamento na nova cultura, mas já despontam como problema especialmente para articulação de opiniões e concretização de projetos políticos no espaço público da sociedade que acolhe os refugiados.

As dificuldades são suficientes para legitimar um momento de afastamento da causa política e concentrar-se na construção de uma base sólida que lhe permita reaver a estabilidade anímica afetada no processo de transição. A despeito das dificuldades, contudo, 
a protagonista não perde de vista o motivo pela qual se encontra no exílio, especialmente porque o trabalho focado de José volta a mostrar-lhe o que têm em comum:

Ela perguntou a José se já tinha encontrado novos amigos. Ele lhe contou que havia relativamente muitos companheiros nessa cidade. Amigos que tinham se juntado para publicar uma nova revista. Para tornar conhecidos a repressão, a tortura e os motivos pelos quais eles abandonaram sua pátria. Para publicar folhetos, imprimir panfletos e preparar noites com palestras informativas. Os companheiros daqui também se envolviam nessas atividades, apoiavam seu trabalho. Sim, também a Diyana conheceria os companheiros, com os quais José trabalhava. E naturalmente também Diyana se envolveria (p. 143).

O espaço do exílio se transforma num campo complexo de possibilidades de ação contra a ditadura e seus métodos de silenciamento. As dificuldades inerentes a reorganização existencial nesse novo contexto social não impedem a José de identificar pessoas com motivações similares e obter os recursos materiais para pôr em prática um aparato de resistência. Ou seja, suas tentativas de apropriação de realidade no exílio passam pelo crivo da atividade política. O olhar que divisa a nova disposição de realidade não para no interesse particular, mas vai além, procurando possibilidades de organizar meios para concretizar um espaço político na pátria que permita a seus cidadãos uma vida digna e o direito de livre expressão.

O estabelecimento existencial na cultura do país de exílio definitivamente significa um grande desafio, pois demanda o reconhecimento de tradições, de estratégias de comunicação, modalidades de ação e interação. Implica também identificar plataformas de encenação pública e abordagem de interesses. Isto é, para que o estrangeiro tenha a possibilidade de articular-se, ele necessita de muito mais que apenas a língua, que por si só já pode representar um grande obstáculo. Todo esse complexo trabalho de compreensão do outro foi realizado pelo protagonista, antes de dar continuidade a seu trabalho político. Com essa bagagem cultural em mãos, ele identifica pessoas com os mesmos interesses, a fim de potencializar seu trabalho, não limitando-se somente a compatriotas, mas procurando também o diálogo com aqueles nativos que apresentam convicções semelhantes. Desse primeiro momento de assentamento e estabilização no espaço social do exílio, o protagonista passa a uma segunda fase de seu trabalho, em que desenvolve um diálogo militante ativo com o novo entorno social, escrevendo, publicando e informando sobres as atrocidades da ditadura militar. Com isso, ele assume a responsabilidade política sobre aquilo que acontece em sua pátria, não delegando a uma instância abstrata e desconhecida o dever de agir. Ao mesmo tempo, responsabiliza-se também pela informação política da sociedade do exílio, visualizando o horizonte do outro e suas limitações. Nisso, não há uma expectativa de que o outro venha a seu encontro ou que interfira, em seu lugar, nas atrocidades que caracterizam a vida política de sua pátria. Ele age, sem delegar responsabilidades, abrindo o caminho também a Diyana para encontrar seu lugar de articulação e militância política no exílio.

Diante desse comportamento, surge uma ética pessoal que lhes impede de enxergar no exílio a possibilidade de conforto pessoal: "Essa responsabilidade jamais podia ser esquecida. Como José poderia se aproveitar aqui das vantagens da sociedade de consumo, enquanto lá 
milhares de pessoa sofriam corporalmente?" (p. 147). Com efeito, o exílio implica também o perigo do esquecimento, especialmente se o entorno social está caracterizado por um comportamento capitalista, cujo fim supremo é o consumo e a satisfação impossível de desejos centrados no ego. Diante das perseguições sofridas na pátria, a imersão nessa cultura de consumo seria, no mínimo, compreensível. Contudo, seu discernimento lhes indica distanciar-se dessa outra forma de ditadura, a fim de não esquecer da dor do outro. Mais uma vez as possibilidades de narrações identitárias arraigadas no projeto pessoal são postergadas, mantendo o foco num objetivo maior que reside no processo de conscientização política.

O movimento em direção ao outro, tendo-o sempre no campo de visão e no cálculo de ações, acaba transformando-se num princípio teleológico que configura e orienta a produção de sentido existencial na identidade dos protagonistas:

Sem dúvida, ela amava José, e de repente ela teve a sensação de estar acordando de um pesadelo, de estar saindo dos escombros de uma casa que desabou. Ela teve que pensar na muitas pessoas soterradas, naquelas que estavam nas prisões escuras, naquelas que foram fuziladas no meio da rua, em rostos conhecidos, em rostos que conhecia juntamente com José:

Sim, José, para todas essas pessoas. Somente assim pode ter um sentido que nós estejamos aqui (p. 144).

A imagem inicial da citação concretiza experiências passadas ainda de maneira disforme, atualizando somente sensações conhecidas. A memória física do passado rapidamente é concatenada e atrelada à experiência da perseguição sofrida pela ditadura. Conjuntamente com a lembrança intensa da ameaça de destruição da dignidade, da autonomia e, sobretudo, do corpo, a memória da dor forma a base para a formação de um horizonte comum. A intensidade dessa experiência não lhes permite conceber uma identidade, em que não figure a narração desses acontecimentos e, ao integrá-los em sua autorrepresentação, surge a necessidade de considerar também a dor alheia. Esta possibilita e fomenta a visão do outro, uma vez que as reminiscências físicas permitem ao sujeito visualizar mais rapidamente as coordenadas do horizonte alheio. Com base nesse passado comum, surge uma imagem do futuro que delineia o sentido existencial do presente. O resultado dessa reflexão pessoal dos protagonistas resulta na constatação de que a presença no exílio só se mostra legítima se lutarem ativamente por uma concepção de realidade em que a ditadura não tenha mais liberdade para destruir àqueles que não se subordinem a sua ideologia. Com isso, a responsabilidade política e a visão do outro se transformam em chaves de acesso e princípio de constituição de sentido pessoal, atrelando a narração de identidade às necessidades existentes num espaço maior que transcende as coordenadas limitadas do indivíduo.

\section{O ESPAÇO DA INTIMIDADE}

Esse último espaço está estreitamente relacionado aos dois primeiros, começando a concretizar-se na pátria, quando os protagonistas se aproximam um ao outro, e estabele- 
cendo-se de forma mais sólida no exílio, quando se deparam com os primeiros conflitos que abalam sua intimidade. A sequência da análise dos espaços, portanto, está atrelada ao desenvolvimento cronológico das personagens, mas também no que se refere a suas dimensões. Eles partem do espaço menor da pátria, estendem-no no exílio e alcançam sua maior extensão justamente na intimidade, pois este os acompanha e os caracteriza em todos os outros.

Esse espaço aborda alguns dos aspectos mais importantes para o pensamento de Özakin como a identidade feminina (WIERSCHKE, 1996b), o feminismo (ADELSON, 1997) e a escrita feminina (SEYHAN, 1997), ou seja, a posição da mulher na sociedade e suas chances de inserir sua voz nos discursos vigentes. A consciência política dos protagonistas potencializa essa discussão e a coloca no centro do espaço íntimo. Como mulher politicamente ativa que abandona seu país em nome de suas convicções, Diyana não está disposta a subordinar-se às vontades do homem nem de curvar-se diante de uma ditadura do patriarcado. Esse posicionamento está bastante claro em sua visão de mundo, mas sua atitude está arraigada num movimento de conciliação que procura auxiliar o outro nos ensaios de interação.

"Você será a dama da casa" (p. 142), uma frase dita impensadamente e de modo jocoso por José desencadeia uma reflexão na protagonista que caracteriza seu comportamento no relacionamento íntimo. Ela se apercebe do tom irônico utilizado pelo companheiro para provocá-la; este está ciente de que ela não deseja identificar-se com esse papel social. Contudo, ela divisa nessas palavras uma verdade que antes não podia imaginar. De fato, ela corre o risco de desempenhar o papel de dona-de-casa no exílio, pois quem trabalha e ganha o dinheiro é José, sem que ela possa mudar essa situação a curto prazo (p. 143). Nesse primeiro conflito que desponta na vida do casal, Diyana procura compreender o que José quis expressar com essas palavras, sem ofender-se com as possíveis interpretações negativas inerentes a elas, mas não deixa de entrever um perigo para sua narração de identidade a ser combatido sem delongas. Há um movimento conciliatório, mas não disposto a renunciar a própria autonomia.

O comportamento patriarcal adotado por José de modo aparentemente jocoso se revela também em outros momentos, despertando em Diyana uma sensação de desconforto que, aos poucos, vai se transformando em algo que já não pode calar. Ainda antes de encontrá-lo no exílio se vê atormentada pelo temor de perdê-lo para alguma mulher no novo país, mas, a despeito desse medo, sabe que ele não se envolveria com uma mulher sem os mesmos interesses políticos e, se não os tivesse, a doutrinaria até que seguisse o mesmo caminho trilhado por ele (p. 140). Nessa atitude, certamente há uma procura por afinidades, mas também uma imposição da interpretação de realidade que questiona os limites do relacionamento. Diyana, de fato, apresenta os mesmos interesses, mas ela vislumbra a possibilidade de que a divergência como tal teria pouco espaço e surgiria como ameaça para a estabilidade do casal.

Isso também vale para outro episódio em que se definem as rotinas da casa e a divisão do espaço. José se sente confortável com a presença de Diyana, mas exige distanciamento quando se dedica à causa política: "Na sua escrivaninha, porém, lhe indicava com seu rosto sério, suas sobrancelhas contraídas e o cigarro rapidamente acendido que não queria tolerar nada em seu espaço que o distraísse” (p. 158). Essa intransigência incomoda a protagonista, uma vez que acabara de chegar e sente a necessidade de alguém para 
conversar. Mais uma vez ela vislumbra a ameaça de instabilidade, se ela não se curvar à disposição de coordenadas e não subordinar-se ao desejo imposto, sem negociações, por uma instância externa. A protagonista vê nessas incongruências entre seus projetos de identidade uma possível ameaça, mas busca visualizar as necessidades do parceiro, a fim de respeitar seus anseios.

Há uma mudança radical nessa atitude, quando ela se apercebe de que o mesmo esforço não parte dele. Isso se dá, sobretudo, na vida íntima. Ela procura compreender o desejo intenso do companheiro, embora não experimente os mesmos anseios (p. 149). Porém quando este procura ignorar as necessidades dela com um comportamento condescendente ( $\mathrm{p}$. 150), procurando silenciar suas preocupações, ela já não pode manter-se passiva, sem pôr em risco a integridade de seu projeto de identidade:

Meus pais estavam acostumados um ao outro e viveram juntos por muitos anos. Mas minha mãe nunca experimentou qualquer prazer ao dormir com meu pai. Pelo motivo, ela não perguntou nem a si nem a meu pai. Meu pai nunca aprendeu a tratá-la corretamente. Mas nós queremos ter outra vida, não é? Se nós nos comportarmos como eles, em todos os sentidos ..... (p. 163).

Essa conversa sobre a vida íntima do casal contém uma série de elementos semelhantes a seu engajamento político. Diyana assume a responsabilidade por sua vida pessoal, sem delegar sua felicidade a um terceiro e sem temer os conflitos que podem surgir desse confronto. Ao abordar sua sexualidade, ela mostra que não está disposta a permanecer calada diante de uma interpretação de realidade unilateral, que não atenta às necessidades do outro. Nessa abordagem, ela enxerga o outro e o inclui em sua visão de futuro, concedendo-lhe a oportunidade de fala e revisão. José a interrompe, colocando a vida política pública no primeiro plano e diminuindo os anseios pessoais expostos pela parceira como algo irrelevante.

Enquanto José separa o dois espaços e procura não mesclá-los, para Diyana essa visão de mundo representa algo insustentável: "Que a vida revolucionária esteja limitada à perspectiva política, me parece artificial. Estou convencida de que uma pessoa que não conhece a si mesma também não pode conhecer a sociedade" (p. 164). Sem temor ante o conflito e sem permitir que seja silenciada pela visão parcial do outro, ela se mostra aberta ao diálogo, enfatizando a responsabilidade mútua. O conflito acaba não resolvido no conto, mas encena contundentemente as dimensões políticas também na vida privada.

\section{CONSIDERAÇÕES FINAIS}

De certa maneira, a protagonista Diyana mostra que a responsabilidade política e a visão do outro começam no próprio sujeito. Ao atentar às próprias necessidades, tentar articulá-las e ir ao encontro do outro a fim de discuti-las, ela cria uma plataforma de negociação, cujo objetivo reside em abrir um espaço social que permita a pluralidade de vozes. Esse movimento de autonomia e de criticidade se revela especialmente complexo, pois envolve a narração de identidade pessoal de cada um dos envolvidos e a narração conjunta do casal. 
Ao questionar o comportamento do companheiro, ela abala a interpretação de realidade existente e exige uma revisão.

Essa mesma exigência tem lugar na pátria, posteriormente, também no exílio, quando José e Diyana questionam a disposição dos fatos, dada pela ditadura em seu país. O governo totalitário da pátria não admite diálogo nem tolera questionamentos, impondo uma única forma de ver e conceber a realidade no país. Ao assumirem a responsabilidade pelo futuro desse espaço, os protagonistas põem em risco a estabilidade de suas identidades, apostando nos benefícios maiores intrínsecos ao diálogo.

\section{REFERÊNCIAS}

ADELSON, Leslie A. The Price of Feminism: Of Women and Turks. In: HERMINGHOUSE, Patricia; MUELLER, Madga (Org.). Gender and Germanness: Cultural Production of Nation. Providence: Bergham, 1997, p. 305-319.

GÖKBERK, Ülker. Encouters with the Other in German Cultural Discourse: Intercultural Germanistik and Aysel Özakin’s Journeys of Exile. In: JANKOWSKY, Karen; LOVE, Carla (Org.). Other Germanies: Questioning Identity in Women's Literature and Art. Albany: State University of New York Press, 1997, p. 19-55.

HENDERSON, Heike. Re-Thinking and Re-Writing Heimat: Turkish Women Writers in Germany. In: Women in German Yearbook: Feminist Studies in German Literature and Culture, 13, 1997, p. 225-243.

REEG, Ulrike. Die Literarisierung fremdkulturell bestimmter Schreibsituationen in den Werken von Aysel Özakin und Franco Biondi. In: FISCHER, Sabine; MCGOWAN, Moray (Org.). Denn du tanzt auf einem Seil: Positionen deutschsprachiger MigrantInnennliteratur. Tübingen: Stauffenburg, 1997, p. 151-164.

SEYHAN, Azade. Scheherazade's Daughters: The Thousand and One Tales of Turkish-German Women Writers. In: BRINKER-GABLER, Gisela; SMITH, Sidonie (Org.). Writing New Identities: Gender, Nation, and Immigration in Contemporary Europe. Minneapolis: University of Minnesota Press, 1997, p. 230-248.

WAGENBAUR, Thomas. Kulturelle Identität oder Hybridität? Aysel Özakins Die Blaue Maske und das Projekt interkultureller Dynamik. In: LiLi: Zeitschrift für Literaturwissenschaft und Linguistik, 25 (97), 1995, p. 22-47.

WIERSCHKE, Annette. Schreiben als Selbstbehauptung: Kulturkonflikt und Identität in den Werken von Aysel Özakin, Alev Tekinay und Emine Sevgi Özdamar. Mit Interviews. Frankfurt: IKO, 1996.

WIERSCHKE, Annette. Ayzel Özakin: Female Turkish Identity between Orientalism and Eurocentrism. In: MIFLC Review, 6, 1996b, p. 19-31. 